\section{HIS MAJESTY THE KING AND THE NEW DEVELOPMENT CODE ${ }^{1}$}

\section{Prawase Wasi $^{2}$}

\begin{abstract}
This paper explores the idea that just as genetic code characterizes life, development code characterizes society. The author draws a comparison between the mainstream or "Western" development code and the "new," more holistic one, as evident in His Majesty King Bhumibol's development plans. He then examines HM the King's "Self Sufficiency Economy" and demonstrates how this new model of development can effectively and positively change the dynamics within the society.
\end{abstract}

\section{Prelude}

Throughout the 60 years of his reign, His Majesty the King Bhumibol has dedicated himself to the country's development in almost all fields, including education, religion, science, technology, arts and culture, agriculture, environment, public health and medicine. This article aims at vertically analysing His Majesty's concepts of national

\footnotetext{
${ }^{1}$ The following is the translation of a transcribed speech given by Dr.Pravet Wasii at the Plaza Athinee Hotel on July 24, 2006, to celebrate the $60^{\text {th }}$ anniversary of HM King Bhumibol Adulyadej's reign. The editorial board of MANUSYA is grateful for Dr.Pravet Wasii's contribution. The translation printed here remains for the most part unedited. ${ }^{2}$ Professor of Medicine, The 1981 Ramon Magsaysay Award for Government Service, The Chairman of Local Development Foudation, Foudation for children, and National Health Foudation
}

development. These "concepts" play key roles as guidelines which are followed during implementation. His Majesty always starts with Sammadithi (right concept), one of the eight noble paths, because the right concept leads to Samma patipada (right implementation). On the contrary, if we start with michadithi (wrong concept), what we do is micha patipada (wrong implementation).

These truths also apply to the country's development; that is, the right concept will lead to right development and the wrong concept to wrong development. Thus, before analysing His Majesty's development activities, we should identify the concepts behind them and compare them with those used in most mainstream, western models of development.

\section{Genetic code characterizes life and development code characterizes society}

On the same plot of land, a variety of trees and plants grow, for example, grass, papaya, mango and coconut. All these trees and plants are different in form and quality, although they are each composed of the same substances and nutrients. This is because each is determined by its DNA (deoxyribonucleic acid). A living thing's DNA determines its development and the food it needs in order to grow. No matter how we might try to change for example, a cat, dog, horse, monkey or human being, it will never change from one species to another because of the specifications of its DNA.

DNA is composed of a base, represented by the letters A T C and G. Each base is formed of 3 letters in different combinations and is 3 billion letters long, for example, ACG AAA ATG CCC GTA. Each set of 
letters is called a triplet code. Each of the 3 billion letters is highly specific; that is to say, if one of them deviates from the original, it is called a "mutation", which likely causes some distortion in our body. Thalassemia genes, for example, are caused by the distortion in one letter of the base. Again, the order of the alphabet base of its DNA determines a living thing's form.

Analogous to the specific order of the DNA base of living things, the question is whether or not there are Development Codes which are composed of specific DNA bases and, thus, bring about different forms of society.

\section{Western $^{3}$ development code}

In the past, human beings lived in different groups or cultural pockets. Culture means the way of life of a community in an environment which is geographically different from one area to another, for example, the earth's poles, deserts, seas, cold and warm zones, mountains and flooded areas. Cultures are naturally influenced by their environment. Because it is impossible for the people near the earth's poles to live the same way as people in the desert, one world culture is impossible.

\footnotetext{
${ }^{3}$ Editor's note: The author distinguishes between what he calls the "Western" Development Code and the "New" Development Code. The former is used to signify mainstream models of development that can be traced back to the Scientific Revolution and the idea of "progress" it engendered, whereas the latter is used to signify an alternative model of development that employs a more holistic approach, as evident in many later development plans, including those of HM the King.
}

Each culture is composed of shared beliefs, values, livelihoods, language, traditions, recreational activities, traditional medicines and environment protections. If all these comply with the environment, a culture can last for thousands of years. Sometimes conflicts, robbery and piracy occur among different groups, but cultures can survive.

Moreover, in each culture, knowledge has been acquired through observation, right and wrong learning, choice making and transfer from one generation to another. This knowledge is given different labels, such as cultural knowledge, traditional knowledge and local knowledge. All refer to the knowledge derived from the mother land and came before scientific knowledge. Cultural knowledge covers a wide range of aspects and activities, for example, the way to earn a living, shelter building, handicraftmaking, aesthetic activities, traditional medicines, conflict resolution and the development of spiritual knowledge. All these have been created and adopted in order to sustain harmony between human society and nature. This harmony, in turn, brought about a new paradigm of thought, which was different from current ones.

"Civilization", is a term that refers to large-scale cultures, for instance, the civilizations of Mesopotamia, the Sindhu River in India and the Huang He River in China. These civilizations date back 5,000 years. What can we learn from these timehonoured civilizations?

Five hundred years ago in Europe, scientific knowledge, which is sharp, clear, deep and alluring, was discovered. This knowledge was further developed and gave birth to powerful technologies, for example, steam engines, fleets made of steel, artillery and machine guns. Such mighty weapons gave Europe unprecedented might. Fleets could 
go anywhere in the world, and no fortresses could resist their artillery and machine guns.

Through these mighty weapons, again, many lives in all lands and on the seas were threatened, including the 5,000-year-old civilization of the Sindhu River and Huang He River valleys. Lands were conquered, and natural resources were taken away. This, was known as colonialism, which brought Europe wealth and prosperity, and created an extremely unequal world.

The production capacity made possible by machinery has caused over-supplies of goods. How to deal with them? The answer is creating and promoting the value of consumption the world over, leading to a culture of materialism and consumerism.

To sustain this civilization, the communication system and capital management must be well grounded. However, due to unequal development and, thus, an unequal world, the capital invested is not distributed but clustered in a big lump somewhere in the world. This big lump can be moved anywhere very rapidly. With advanced knowledge, investors or fund managers can siphon off more and more money and resources from anywhere in the world to make a bigger lump. This process has led to capitalism or moneyism, and brought about a new civilization, which prevails the world over. This civilization is composed of materialism, consumerism and moneyism.

From the process above, it can be summed up that in contemporary civilization, Knowledge leads to Power and Money, encoded as the KPM development code. This code moves from $\mathrm{K}$ to $\mathrm{M}$ or, in reverse, from $\mathrm{M}$ to $\mathrm{K}$ and then to $\mathrm{P}$.

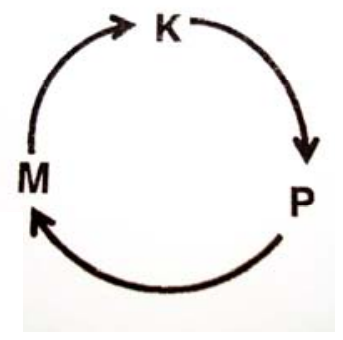

Picture 1: the cycle of KPM

The cycle can be explained as follows: Power and Money determines the kind of knowledge to be sought after; that is, the knowledge that enhances power and money. Arguably, knowledge developed freely. However, having been exploited to build and strengthen the structure of Power and Money, Knowledge or science will be determined by Power and Money. Thus, a lot of studies and research, intentionally or unintentionally, are dominated by Power and Money.

\section{The crisis of Western civilization and the search for solutions}

Arguably, Western or modern development has brought about a myriad of advantages, including machinery, transportation and medical science. However, disputes about the righteousness and contributions of free trade or financial agreements and the consequences derived from this development cannot be denied. These are as follows:

1. the widening gap between poor and rich people

2. large-scale environmental destruction

3. cultural and spiritual destruction

4. severe social crises

For (1), it can be seen that the gap between the poor and the rich is growing 
increasingly wide. Nowadays, the richest 200 Americans combined are equal in worth to 2 billion people. At the lowest point of the gap are those drowning in debt, and at the highest point are those with billions of dollars. Meanwhile, the number of homeless people has increased. In Thailand, the poorest $20 \%$ of the population earn less income than before. The ever-widening gap causes social and political injustice and, thus, various crises.

(2) In Thailand, with its size of 321 million rai, 50 years ago 220 million rai or $60 \%$ was forested. Through the so-called modern development, only 80 million rai or just $20 \%$ is left. This has made the poor poorer because their lives depend on the forest. Moreover, it has caused forest imbalances. Droughts are more severe and last longer in the dry season, and in the rainy season, floods are higher and they last longer. Soil, water and air are polluted. These cause harm to health and contribute to global warming, which will possibly cause global flooding in the future. This environmental crisis is a global problem which is difficult to solve because human beings indulge in overconsumption.

(3) Development based on materialism, consumerism and moneyism is locked in the shallow and narrow material world, and devastates vertical development, i.e., spiritual and cultural development. As mentioned before, culture means a way of living in compliance with the environment. Spirituality is goodness which human beings cannot afford to lack. Without spiritual learning, we cannot be good human beings. Therefore, the devastation of our cultural and spiritual heritage has brought about crises in every social dimension.
(4) These social crises can be perceived as social disintegration, which is manifested in different crises, for example, destabilized family and community, urban poor, crime, prostitution, drugs, AIDS, suicide and war.

Many Western philosophers, for instances, Laszlo, Grof and Russell view Western civilization as making the world incurable unless there is a spiritual revolution. The Dalai Lama said that our world suffers from spiritual deficiency disease and badly needs a spiritual revolution. The Venerable Buddhadasa predicted the current social crisis for so long and asserted that there were no other remedies than spiritual ones. He insistently taught, "If morality doesn't return to the world, the last day is not an exaggeration." Albert Einstein said, "A new paradigm of thought is needed if we want to survive." In all, if we cannot break through the old paradigm, the current crises cannot be solved.

Contemporary literature on 'New Consciousness' and the importance of spirituality is prevalent. Examples include: Megatrend 2010-Conscious Capitalism and Spiritual Politics-Changing the World from the Inside Out. These books can be perceived as a trend in searching for a way out of the current crises derived from materialism, consumerism and moneyism.

\section{King Bhumibol and the new development code}

The development code reflects the concept of development and, thus, governs implementation and its outcome. It can be seen that His Majesty's development code is fundamentally different from the mainstream, Western one. To understand His Majesty's development code, royal speeches, writing and works shall be investigated. 
An excerpt of His Majesty's address to former students granted the Anandamahidol Scholarship states: "No matter how outdated they call us, what's more important is having enough to live on and to consume, and being kind to one another." This shows us a different society from the current free trade one. "Outdated" means not modern. "Having enough to live on and to consume, and being kind to one another" means living together, not cut-throat competition. Let me cite another royal speech "Giving Sustains Thailand", given 30 years ago on the occasion of the grand opening of the Research and Development Institute (RDI), Khonkaen University. At that time, some development economists said that the agricultural sector would play a less important role. On visiting the exhibition of agricultural life and work, His Majesty said, "Agriculture plays a no less important role because it involves many people. Thinking of only money we cannot survive. As for industry, we must take into account environmental destruction because solving environment problems is very expensive." Throughout his reign, His Majesty has always paid attention to agriculturists and lent both moral and technical support, researched and tried by His Majesty himself in various fields. These include: plant and animal nurseries, irrigation, synthetic rain, agricultural training stations in each region as well as in-house farming at Chitralada Palace. The message His Majesty most likely wants to convey to us is nothing less than the strength of agricultural society, which forms the base of our country. We must not abandon agriculture and flock to industry because of money-the main objective of the current development code.

Paddle back into the canal. In another address, His Majesty said, "We should paddle back into the canal because the waves are milder and, thus, safe." This means if we paddle out into the storm, huge waves will probably sink our boat. In fact, this old Thai proverb, "paddle back into the canal," has a negative meaning. It means stepping back to a less developed world. His Majesty, however, reversed the negative to a positive meaning and implied a warning.

In an episode from His Majesty' composition, Bra Maha Janaka, 700 hundred merchants, greedy for treasure, sail into a storm on their way to Suvarnabhumi. The ship, at last, sinks; all of them ask a goddess to help them, but are denied. All of them die at sea. In contrast, Bra Maha Janaka is determined to rely on himself with true perseverance.

Bra Maha Janaka has an extreme view that all human beings live in avijja. According to Buddhism, avijja means ignorance and indifference to suffering, social disruptions, and crises. They have built the city of avijja, which is full of evil and wicked deeds (see the illustrations in the composition). The opposite of avijja is "vijja", which means wisdom to unchain themselves from ignorance. Therefore, if the society falls victim to avijja, wicked deeds prevail.

In His Majesty's composition, the term Maha Vijjalaya is used, instead of the word Maha Vidyalaya, which means university. It can be inferred that the knowledge acquired from the university is not enough to overcome avijja (ignorance). To put it more clearly, although there are a lot of renowned universities to which clever people go, we are never wise in solving the country's problems.

Again, through the KPM development code, knowledge is used but leads the world to crisis because knowledge is not powerful 
enough to overcome ignorance. Wisdom should be brought in.

\section{His Majesty's Development concepts and initiatives culminated in "Self Sufficiency Economy"}

For more than 30 years, the self-sufficiency economy has been implied in His Majesty's addresses and speeches, for instance, as mentioned before: "No matter how outdated they call us, What's more important is having enough to live on and to consume, and being kind to one another". We can not view and treat the economy just as a matter of technique. If we do, our vision may be blocked and we may go the wrong way. The self-sufficiency economy is a new paradigm. As Einstein once said, "If we want to survive, a new paradigm is needed."

Together with a new paradigm, a new question is posed. The question posed in the mainstream economy is different from that in the self-sufficiency one. To be clear, for the former, the question is "how can we increase wealth?" or "how can we be rich?" but for the latter it is "how can we be good?" If the former question is asked, we are led to deterioration; in contrast, if the latter is asked, we are led to the selfsufficiency economy.

Therefore, the development code of a selfsufficiency economy, with its focus on Goodness, Community or Culture and Knowledge (GCK), definitely contrasts with the mainstream, Western one.

\section{New questions of the society}

In the world of materialism, consumerism and moneyism, we are intentionally or unintentionally lured to the question above: "how can we be rich?" If this is given priority, we are probably ready to do anything bad to reach the aim, for example, environmental destruction, overprofiteering, exploitation of children and women, cultural deterioration, promotion of gambling, drug trafficking and corruption. All lead to immorality.

If the question "how can we be good?" is given priority and is properly posed, the answer is not difficult: To be good involves:

- perseverance and self-reliance

- frugality

- honesty

- loving kindness to one another

- environmental preservation

- cultural preservation

- $\quad$ spiritual learning

- learning how to be good

If we keep the above-mentioned points in mind, we are self-sufficient and never poor. Suppose that we work hard, persevere and are frugal, how can we fall into poverty? The other points also favour co-existence between human beings and the environment, as well as spiritual learning. This results in balance, sufficiency, plausibility and life quality.

On the contrary, if "how can we be rich?" is asked, we easily fall victim to poverty. This is because those richer, stronger and higher in status usually take advantage of the poor and, as a result, the gap is widened. 

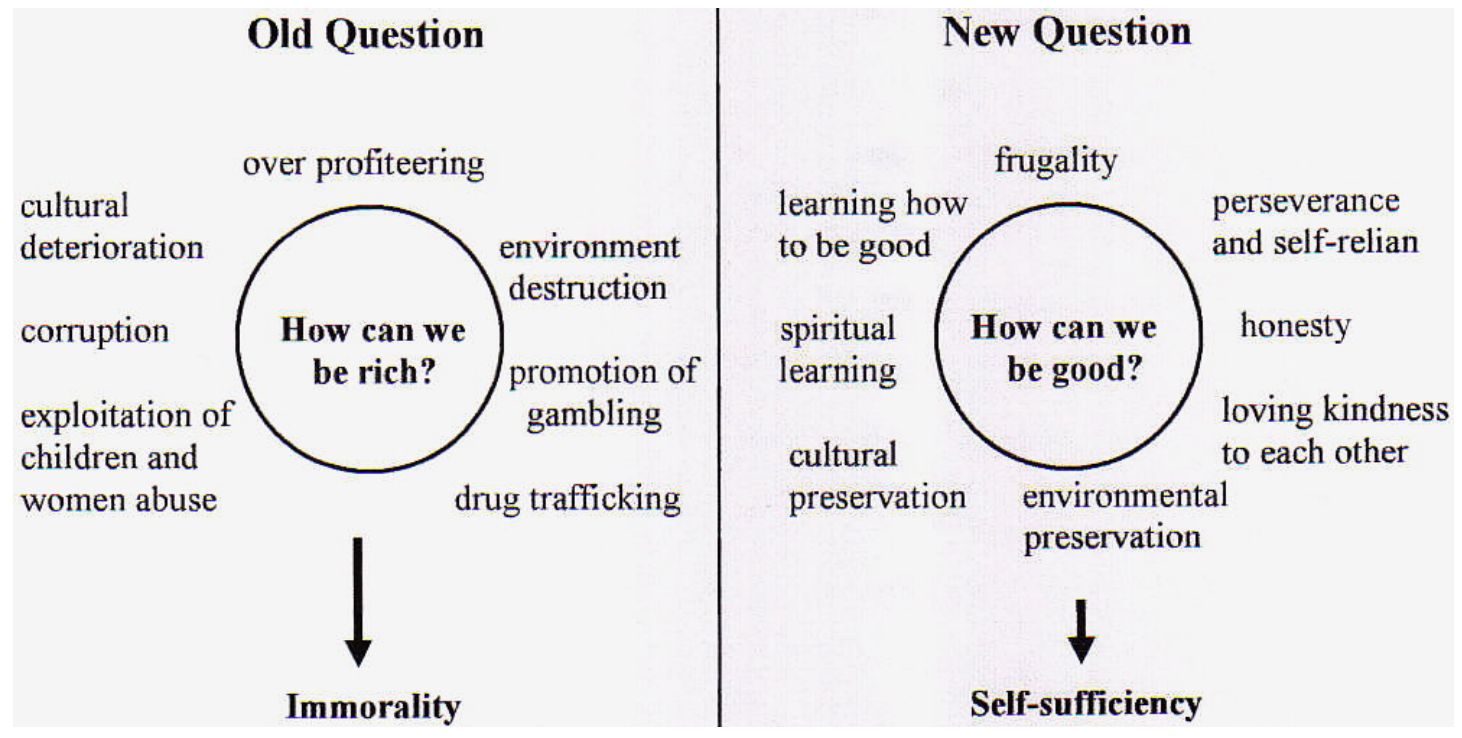

Figure 2: old and new questions

Although the idea of self-sufficiency was initiated by the King and has been mentioned and talked about for a long time, not too many people paid attention to it because most are influenced by the mainstream, Western economics. When the crisis struck in 1997, self-sufficiency was heard again but it seemed hard to conceive because the mainstream, Western paradigm has already dominated our economic structure, ways of thought and livelihoods.

Such a stiff structure cannot be easily dismantled just by means of different techniques; it requires a new paradigm, called self-sufficiency. Self-sufficiency is not a matter of technique, and to understand it, the new question "how can we be good?", instead of "how can we be rich?", must be posed. If "how can we be good?" is reiterated, our mentality can gradually change. Then lifestyles, the educational system, and relations between human beings and the environment will be adjusted accordingly. All these, finally, lead the way to self-sufficiency.
For pragmatists, some doubts as to the adoption and implementation of selfsufficiency are cast. These will be discussed below.

\section{Goodness-Community-Knowledge (GCK): A new development code}

The idea that good development cannot be based on knowledge seems strange and unacceptable because the importance of knowledge has been emphasized throughout our lives in the educational system. It does not mean that knowledge is not important but it should not be given sole preference. This is because knowledge is vulnerable and can easily succumb to greed. It intertwines with power and money, forming the development code KPM (KnowledgePower-Money). The current educational system rarely contributes to the grassroots community but only to the state (power), commercial and industrial sectors (money).

Unlike the KPM paradigm, GCK gives priority to the harmonious relationship 
between human beings and the environment because it brings about favourable social conditions, for instance, reciprocity, negotiation, mediation, sharing and allocation of natural resources. Figure 3 shows this condition.

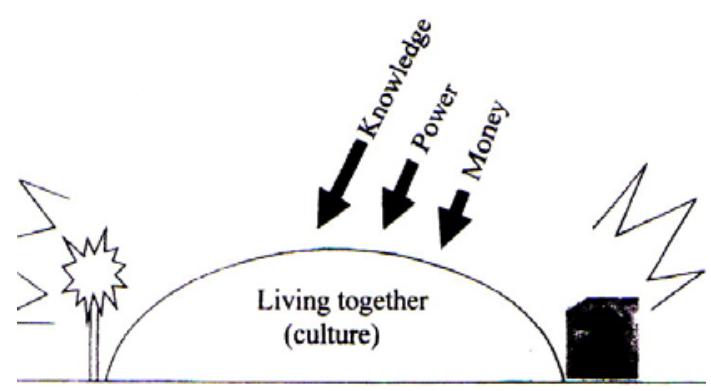

Figure 3: conventional lifestyles are formed and led by the culture in compliance with the environment. Knowledge, Power and Money are external factors which attack the condition of living together.

As mentioned in the preceding parts, Knowledge, Power and Money are external factors which are peculiar to Goodness, Community and Knowledge. They threaten the environment, culture and spirituality.

The free trade regime promotes individualized consumerism and the community is dismissed just like local groceries, which once were self-sustainable but have been crushed by mega-stores. We gain convenience at the price of community life, and most of the profits go to overseas investors.

It seems that the overseas investment, by its size, is irresistible unless the strength of communities, i.e., the sense of shared cultural life, is revived. To be clear, the world cannot survive the crisis unless we change from the individualized, unshared worldview to a sympathetic, shared one.
In the new development code, what follows Goodness $(\mathrm{G})$ is Community or Culture (C). Knowledge (K) then follows Culture or Community (C) to enhance Goodness $(G)$ and communal existence. If things take this path, the risk of social problem is minimized. However, it should be made clear that Knowledge can be classified into 2 types:

1). Internal or personal knowledge (cultural knowledge)

2). External knowledge (scientific knowledge)

Internal or personal knowledge is gained from work and experience; in other words, it is derived from culture. In contrast, external knowledge is derived from scientific research. The former is embedded in all people but the latter is accessible to few people.

If internal knowledge is given priority as the basis of development, it will harmonize with culture. As a result, people will be confident and proud of themselves. Then external knowledge can be used to complement internal knowledge. Moreover, the societal landscape will be changed because knowledge management is based on a respect for human beings. This strengthens the nation.

In reality, external knowledge is given priority while internal knowledge is dismissed. Thus, most people are neglected and cannot be proud of themselves. As a result, the nation is weakened.

In Bra Maha Janaka, bio-technology is used in breeding plants, preserving and increasing natural resources and maintaining the natural balance. It can thus be inferred that His Majesty also gives priority to internal knowledge, i.e., he is interested in different modern fields of knowledge and 
in making use of them for the happiness of living together.

Goodness means wisdom or pañ̃nya, which covers the ability to ponder and do good deeds. Therefore, pañnya consists necessarily of morality and ethics. However, people often confuse paññya with Sati paññya, which means external knowledge and is relatively limited. In other words, Sati pañnya puts an emphasis on external knowledge without integrating morality and ethics.

As for the GCK development code, only G (Goodness) or the whole GCK can be considered as wisdom because both Culture (Community) and Knowledge are governed by Goodness.

In investigating His Majesty's works and concepts of national development, it becomes clear that the holistic approach should be adopted. In other words, they are based on a new paradigm, which is different from the mainstream KPM paradigm. If the new GCK development code is adopted, there is a strong possibility that society will be changed in the same way as the genetic code can determine life.

\section{The path of self-sufficiency}

To change from the mainstream paradigm (materialism, consumerism and moneyism) to self-sufficiency is a Gordian knot due to the fact that the former is deeply rooted not only in a given country but the world over. Therefore, a new paradigm must be adopted as offered below:

1. Cultivating new concepts and consciousness

2. Designing a proper development structure
3. Promoting contemplative education

4. Creating new social tools

\section{Creating a new concept and consciousness}

Because self-sufficiency is a new paradigm of living, the new question "how can we be good?" should be promoted and "how can we be rich" demoted. If the former is reiterated, people will gradually accept and adapt to the concept of goodness and living together, instead of maximum profitability. Organizations and corporations will no longer be profit hunters but conscious corporations seeking to promote goodness and harmonious living.

Again, in the GCK development code, Goodness is the foundation, Community the aim and Knowledge the tool. These result in self-sufficiency.

\section{Designing a proper development structure}

A proper development structure is not difficult to conceive. Nowadays, we have a lot of tools, for example, hammers and nails, but we lack proper designs. To craft an elephant or a Buddha image, a proper design is indispensable. Technologies give us the power to do anything if they are properly used.

What is a proper development structure? Like any structure, whether a pyramid or a pagoda, a firm foundation is the most important part. Likewise, societies need a firm foundation for further development. If the foundation is smaller than and asymmetrical to the upper parts, the society will collapse-a situation we are facing today. This is because social development is based on capital foundation. 
What is a society's foundation? A society's foundation is a stable local community, which always forms part of a good democratic community. Only a stable community can integrate different social dimensions, such as economy, family, community, environment, culture and health, in solving social problems. This, then, leads to a peaceful community.
All development must be based on and enhance the society's firm foundation, which we lack nowadays. Therefore, most current development today is scattered and lack clear directions. See figure 4.

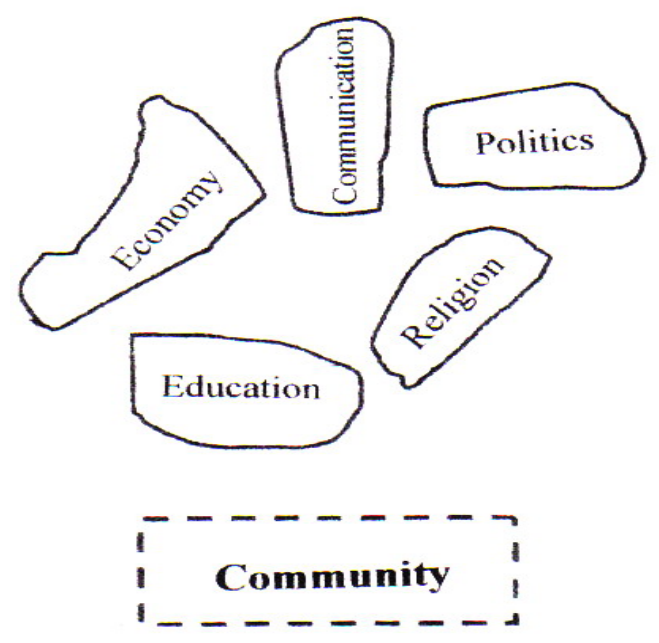

A). development without a firm foundation

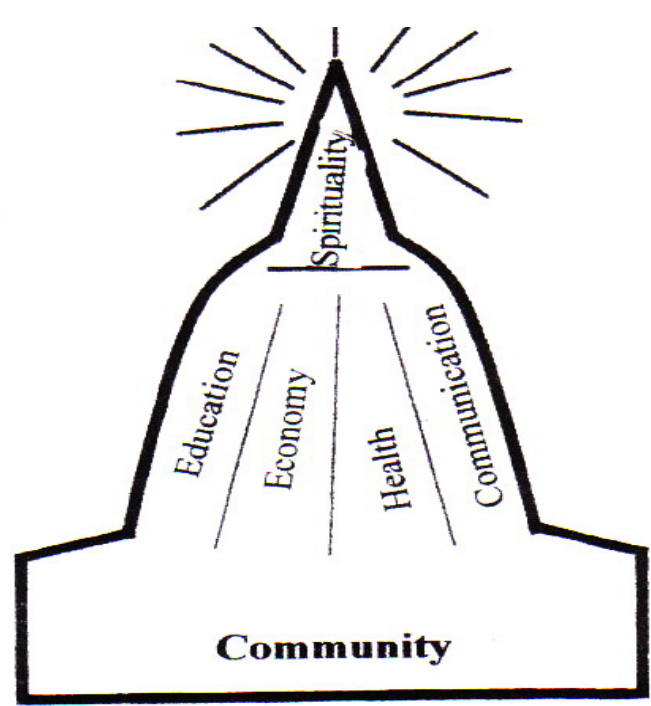

B). development with a strong social foundation

Figure 4: The proper development structure is 4 B. To put it clearly, the foundation or local community of the pagoda must be stable and linked to different developments.

A stable community is the foundation of self-sufficiency. It can be built up through sharing, brainstorming and cooperation among people in the community in structuring and implementing development plans. This will unchain people from poverty, teach them how to deal with such social problems as violence and drugs and to preserve the environment and culture, and pave the road to self-sufficiency.
In integrated development, locality is given priority. Only a given department of a ministry cannot take up and implement a development task because it has a limited scope of responsibility. Moreover, universities should play a role in strengthening the local community. If universities are in touch with local communities and help promote community strengths, they will become essential to self-sufficiency development. 
If we understand the importance of the local community or the social base we should understand why His Majesty has made endless journeys through the country and dedicated himself to the grassroots people.

If development, whether the economy, education, religion, public health or communication, contributes to the base of society or to the poor, all types of development will be more efficacious. Let the upper and lower contribute to each other and our country will become strong, sufficient and prosperous.

\section{Promoting contemplative education}

Today only non-spiritual subjects and fields are given priority and, therefore, the spiritual potential of human beings is not explored. The different crises we face now cannot be solved by scientific knowledge but by spirituality. That is why a fundamental transformation, both personal and organizational, is needed. Otherwise, we will not survive. In other words, apart from the external world, people should strive for an internal transformation, which is achieved through contemplative education. This can be realized through access to truth. As a result, we will learn to be free and happy and to love each other and nature.

To access truth, various approaches are available, for example, meditation, arts, environment, work, society and science. Access to truth can lead to instant happiness, which is inexpensive, environmentally friendly and available to everybody. This is self-sufficiency, which can be reached by a fundamental transformation.

In today's world, the quest for spiritual transformation goes by many different names, for instance, new consciousness, universal spirituality, spiritual development, aesthetical dialogues and U-Theory. Some simply call it Buddhist mindfulness.

At the University of Massachusettes, 87,000 students once registered for the course "Buddhist Mindfulness." In California, an increasing number of people are attending training courses on the new consciousness offered by the Institute of Noetic Sciences (IONS), a center for new consciousness research.

Obviously, spirituality or the internal world is a new trend for coping with MaterialismConsumerism-Moneyism.

Contemplative education does ease the process of adjustment to self-sufficiency, and thus should be promoted.

\section{New social tool}

In today's complex society, the social problems we face are structural ones, for instance, poverty, social prejudice, human rights violation, drugs and moral deterioration. It seems that almost all social institutions (the political system, education, business and religion) are too vulnerable to cope with this deterioration.

To cope with the problems mentioned above, we need to investigate the causes of this vulnerability and promote organizational innovation.

\section{Vertical organization}

It can be said that most organizations have a vertical or top-down structure, in which rules and orders must be strictly followed. Such organizations are not strong enough to confront the complexities of contemporary society. 


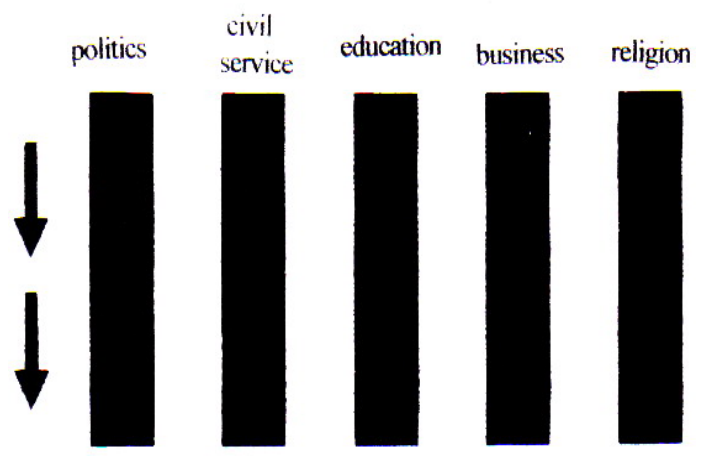

Figure 5: All organizations are vertically structured and they are not powerful enough to solve complex problems.

Arguably, the government is equipped with legitimate power which can be exercised, but not in every case. Some complicated problems need time to be understood and cooperation to be solved. However, the chance of learning is very often not made available in a vertical organization because those at the top of the hierarchy would rather issue commands than cooperate. Therefore, the organization is blocked by rules and orders.

This results in even less cooperation, working inertia, connection seeking, domination, bluffing, and quarreling. In the end, nobody is happy, and nobody is willing to take part in building a good society.

An organizational transformation is needed. This does not mean that all of the old systems must be rooted out. In other words, although the old system is demolished, old faces and thoughts return. What is important is an individual-based or spiritual transformation.

To transform any organization, a horizontal structure must be adopted, i.e., each individual is honoured and capable of sharing and participating in any activity. This leads to organizational networking and a new social structure, called INN.

$\mathrm{I}=$ individuals, who are honoured, valued and have the potential to do good. A new consciousness will free them from the blocked society and lead them to happiness.

$\mathrm{N}=$ Nodes, referring to various groups of like-minded people sharing something. People in each group will be happy and creative because they exist in horizontal, equal relationships.

$\mathrm{N}=$ Networks, referring to linkages both among individuals and among different nodes.

Figure 6 illustrates horizontal organization, in which nobody controls anyone else but in which they learn together. This new organization and society will be filled with love, happiness and wisdom and, thus, it will be strong enough to cope with complex social problems.

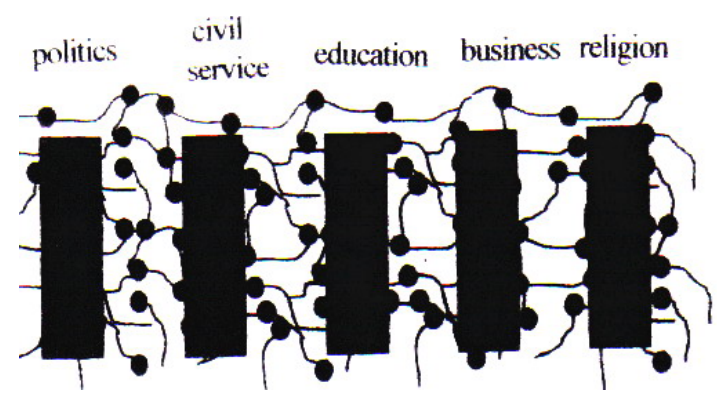

Figure 6: individual capability and social networking-horizontal relationships

Individual capability, grouping and networking will bring about a new horizontal relationship without destroying the existing structure. 
Again, this fundamental transformation on both individual and organizational levels provides us with a solution to our current social crises. If the concept of transformative learning is brought into the current educational system, society will become powerful enough to survive crises. Then, we can create a self-sufficient society whose members are happy.

Existing power structures should be changed from vertical to horizontal ones; that is, sharing and networking are given preference over commanding.

The four paths mentioned above will lead to change at the conceptual level and, as a result, to a right development structure. Moreover, the fundamental transformation on both individual and organizational levels will lead us to self-sufficiency and peace.

\section{Epilogue}

As a result of His Majesty's projects and work throughout the 60 years of his reign, a new paradigm has been introduced and adopted in different fields. Goodness becomes the base and the aim is to live peacefully together by means of knowledge. This can be coded as GCK (GoodnessCommunity-Knowledge). Through GCK, we are more likely to survive the current social crises.

On the contrary, the conventional, mainstream paradigm, which is coded KPM (Knowledge-Power-Money), leads us closer and closer to global crisis and, immorality. This is because money is given priority.

If we want to heal the world, we are more likely to succeed if we adopt the new GCK development code.
It is this code which informs His Majesty's concept of development. 